\title{
Knowledge of Vasectomy and its Associated Factors Among Married Men in Debre Tabor Town, Northwest Ethiopia: A community Based Cross- sectional Study.
}

\author{
Alemu Degu Ayele ( $\nabla$ degualemu53@gmail.com ) \\ Debre Tabor University \\ Fentahun Yenealem Beyene \\ Bahir Dar University \\ Bekalu Getnet Kassa \\ Debre Tabor University \\ Gedefaye Nibret Mihretie \\ Debre Tabor University
}

Research article

Keywords: Vasectomy, knowledge, Debre Tabor

Posted Date: July 30th, 2020

DOI: https://doi.org/10.21203/rs.3.rs-49947/v1

License: (c) (1) This work is licensed under a Creative Commons Attribution 4.0 International License.

Read Full License 


\section{Abstract}

Background: - Even though vasectomy is one of the safest, simple and most effective family planning methods available for men, it is one of the least used contraceptive methods in developing world including Ethiopia. The main reason for low level use may be low knowledge about vasectomy among men. This study was therefore designed to assess knowledge of vasectomy and its associated factors among married men in Debre Tabor Town.

Methods: - A community based cross-sectional study was conducted among 418 married men from December $05-25,2019$. Simple random sampling technique was employed. Data was collected by face to face interview using structured and pre-tested questionnaire. Data was entered using Epi- Data version 4.2 and analyzed by SPSS version 23. The association between variables was analyzed using bivariable and multivariable logistic regression model. Finally variables having $\mathrm{p}$-value $<0.05$ at $95 \% \mathrm{Cl}$ were considered as statistically significant.

Results: A total of 418 participants were included with response rate of $98.8 \%$. The mean age of participant was 38.06 (SD \pm 6.873 ) years. About $60.5 \%$ of men had ever heard about vasectomy. Men mentioned health care providers as main source of information. Among those who had ever heard, only $58.8 \%$ defined vasectomy correctly. About $25.6 \%$ equated vasectomy with castration and about $15.6 \%$ described as "it is making the man impotent. In this study, only $38.5 \%$ of men were knowledgeable about vasectomy. Multivariable logistic regression showed that completing secondary education (AOR= 4.70, 95\% Cl: 1.26-17.55), attending college and above (AOR=8.36, 95\% Cl: 2.41-28.97)), having 4 or more alive children (AOR=0.51, 95\% Cl: 0.29-0.89) and positive attitude (AOR= 2.47, 95\% Cl: 1.58-3.86) were significantly associated with knowledge of vasectomy.

Conclusions: In this study level of knowledge of married men about vasectomy was low. Educational status, number of children and attitude were statistically significant with men knowledge about vasectomy. Emphasis should be given on improving the educational status of men to improve their knowledge, and positively changing the men upbringing culture right from their childhood which will also improve their attitude towards vasectomy in the future.

\section{Introduction}

The number of world population is increasing from day to day. In 2050 it is expected that it will reach to 9.9 billion and Africa's population will be more than double[1]. In Africa Ethiopia was the second populous country next to Nigeria with estimated population of 101.7 million in the mid-2016[2]. The country is also affected by high maternal morbidity and mortality related to unintended and unwanted pregnancies[2, 3]. The goal of family planning all over the world has attracted attention due to its importance in decision making about population growth and development issues[4]. Globally, using contraceptive potentially reduced maternal mortality by $44 \%[5]$. 
Despite the 1994 International Conference on Population and Development (ICPD) in Cairo emphasized that, men's involvement in sexual and reproductive health issues is very imperative for better outcome and set clear directions to increase men's participation in family planning, male involvement in family planning is still very low in Africa [6-8].

Vasectomy is a men permanent contraceptive method after completing their desire number of children which is known and acceptable only in some developed countries of the world. Although it is safe and easy to perform, only 45 million couples worldwide rely on it $[9,10]$.

International health organizations in recent years have suggested that involvement of men on the utilization and promotion of contraceptive methods is very crucial to provide couples with more maleoriented contraceptive choices, such as vasectomy. Even though its procedure is simple and easy with a high success rate $(>99 \%)$ and minimal complications, it is underutilized around the world, especially in developing countries including Ethiopia [11-13].Studies in African countries showed that knowledge of vasectomy is low[14-16].

Ethiopia has a target plan to increase the contraceptive prevalence to $55 \%$ by the year 2020 [17]. To achieve this goal the government in collaboration with other stack holders focuses on diversifying the FP method mix by increasing demand and access to long-acting and permanent methods[18].Due to this effort, contraceptive prevalence rate (CPR) was reached to $41 \%$ in 2019 from $35 \%$ in 2016, but the method mix is still dominated by short acting female dependent methods such as injectable (27\%), followed by implants (9\%)[19].

Different reviewed literature report showed that level of knowledge about vasectomy was associated with different variables [20-25]. Educational status, occupation, Cultural beliefs, societal norms, number of live children, and attitude were found to be predictors of level of knowledge about vasectomy.

According to 2016 Ethiopian demographic and health survey (EDHS) report only $11.3 \%$ married women and $23.5 \%$ married men were heard about vasectomy[26]. A more recent studies in Gondar Town and Dangila Town, Northwestern Ethiopia identified that only $13.3 \%$ and $44.8 \%$ of married men had good knowledge about vasectomy $[24,25]$ respectively. The reason for low level of vasectomy use in Ethiopia may be low level of knowledge about vasectomy. There are few studies on knowledge of married men about vasectomy in Ethiopia. The major one is the 2016 EDHS report. But this report assessed only whether men and women had heard about vasectomy. Therefore this study was designed to determine men's level of knowledge about vasectomy and identify factors associated with knowledge about vasectomy among married men in Debre Tabor Town, Northwest Ethiopia.

\section{Methods}

\section{Study design an setting}


Community based cross-sectional study design was conducted in Debre Tabor Town from December 0525,2019 . The town is found in Amhara region and it is a capital city of South Gondar Zone, Northwest Ethiopia. It is located 665 kilometers Northwest of Addis Ababa (the capital city of Ethiopia), and $103 \mathrm{kms}$ Northwest of Bahir Dar. The town has six small administrative units called kebeles with a total population of 92,530 based on 2018 report of town administration[27].

\section{Study population}

All marred men whose wives were in reproductive age group living in all six kebeles of Debre Tabor Town were the study population. All married men whose wives were in reproductive age group in the town within the study period were included. Whereas married men whose wife were in reproductive age group who were critically ill (bed reddened), had already done vasectomy, had infertile wife, had wife with hysterectomy and live less than 6 months during data collection period in Debre Tabor Town were excluded from the study.

\section{Sample size and sampling procedure}

EPI-INFO version7.0 statistical software was used to calculate the sample size assuming that $44.8 \%$ of men were knowledgeable about vasectomy[25],95\% confidence interval with 5\% margin of error it becomes 380 . By adding $5 \%$ non-response rate the final sample size was 418 . Simple random sampling technique was applied to select 418 married men. A total of 14,088 households and 14,614 married men were living in the tow[27]. A household was sampling unit in each kebeles and samples were allocated proportionally to each kebeles based on their total household number. Household numbers with married men in each kebeles was found from the kebeles registration book. Then study households were selected from each kebeles through simple random sampling technique by using table of random numbers starting from kebele one from a random start point. The first household was selected in each kebele by using lottery method. One married man per household was interviewed. When two or more eligible men were found in one house hold, only one was interviewed by lottery method and if no eligible men were identified in the selected household, the next eligible household located in the clockwise direction was visited and included until we got the desired sample size.

\section{Operational definitions}

Knowledg e: - In this study knowledge about vasectomy was determined by using 9 knowledge related questions. A value of 1 and 0 was given for each correct and incorrect answer respectively and labeled as good knowledge; those individuals who answered at least 5 knowledge related questions and poor knowledge; those answered less than 5 knowledge related questions[25].

Attitude: - In this study attitude of study participants towards vasectomy was also determined by using 9 attitude related questions and labeled as positive attitude; those participants who scored greater than or equals to the mean score and negative attitude; those individuals who scored less than the mean score[28]. 


\section{Data collection procedures and data quality control}

Data were collected via face to face interview techniques using a structured, validated and pretested questionnaire prepared after intensive review of relevant literatures. The questionnaire was first prepared in English and then translated to local language Amharic for simplicity and back to English to maintain its consistency by two language expert individuals who speak both English and Amharic fluently. The information was collected on participants' socio-demographic characteristics, reproductive characteristics, knowledge related characteristics and attitude related characteristics. Pretesting of the questionnaire was done on $5 \%$ of participants ( 20 married men) in Gassay Town near to the study setting. During the pre-test, the questionnaire was assessed for its clarity, accuracy of the knowledge measured and comprehensiveness, readability and the optimal time for completing the interview. Modifications and corrections like; wording, logical sequence and skip patterns were done immediately based on the result. The data was collected by four diploma health professionals and supervised by two trained health professionals who had BSc. Data collectors and supervisors were trained for one day on aim of the study, method of data collection, contents of the questionnaire, how to keep confidentiality, responders' right, and informed consent before they start the data collection. The completeness and consistency of data was cross-cheeked, cleaned and compiled on a daily basis by supervisors and principal investigator. The overall activity was supervised by the principal investigator of the study.

\section{Data Processing and analysis}

The collected data were coded and entered by using Epi-Data version 4.2 and then exported to SPSS version 23 for analysis. Descriptive statistics analysis was carried out. Tables and percentages were used to describe the data. Bivariable logistic regression analysis was executed by computing odds ratio (OR) with $95 \%$ confidence interval to see the association between each independent and dependent variable. Then variables that showed association in binary logistic regression analysis and which have P-value less than 0.20 were entered into multivariable logistic regression model for further analysis by controlling confounding factors. Finally adjusted odds ratio (AOR) with $95 \% \mathrm{Cl}$, P-value less than 0.05 was considered as statistically significant.

\section{Ethical consideration}

Ethical clearance was obtained from the institutional ethics committee of Debre Tabor University. In addition a support letter was granted from Debre Tabor Zonal Health Office and administrative office of the town. Participants of the study were informed about the purpose, objectives and their right to participate or not participate in the study and then written informed consent was obtained from each participant. Privacy and confidentiality were ensured by keeping all information anonymous.

\section{Results}

\section{Socio-demographic characteristics}


A total of 418 married men were participated in this study with response rate of $98.8 \%$. Of these near to half of the respondents 197 (47.7\%) were belonged to the age group of 31-40 years with a mean age of $38.06(S D \pm 6.873)$ years.

Majority of the participants, $400(96.9 \%)$ were Amhara by ethnicity and orthodox Christians followers, $365(88.4 \%)$. In addition, more than half of the participants, $266(64.4 \%)$ and one hundred ninety $(46 \%)$ participants wife were attended college and above by their educational status. Two hundred fifty-one (60.8\%) participants were civil servant by occupation (Table 1).

\section{Reproductive characteristics of participants}

Among the respondents, $146(35.4 \%)$ were living with their wife from 6-10 years with average duration of marriage 9.86 year. Two hundred fifty-eight (62.5\%) of participants had three and more alive children. Majority of the study participants, $370(89.6 \%)$ were discussed about FP with their partner. One hundred twenty-four (30\%) participants were completed their family size. Among $289(70 \%)$ participants who had not completed their family size, $210(72.2 \%)$ participants had a desire number of three children for their future life (Table 2).

Table 2: Reproductive characteristics of married men in Debre Tabor Town, Northwest Ethiopia, December, 2019(N = 413). 


\begin{tabular}{|lll|}
\hline Variables & Frequency & Percent (\%) \\
\hline Duration of married year & & \\
$\leq 5$ years & 95 & 23.0 \\
\hline $6-10$ years & 146 & 35.4 \\
\hline $11-15$ years & 99 & 24 \\
\hline$\geq 16$ years & 73 & 17.6 \\
\hline Number of living children & & \\
\hline$\leq 3$ children & 258 & 62.5 \\
\hline$>3$ children & 155 & 37.5 \\
\hline Discuss abort FP with partner & & \\
\hline Yes & 370 & 89.6 \\
\hline No & 43 & 10.4 \\
\hline Complete family size & & \\
\hline Yes & 124 & 30.0 \\
\hline No & 289 & 70.0 \\
\hline Future desire no of children(N = 289) & & \\
\hline$\leq 3$ children & 210 & 72.2 \\
\hline$\geq 4$ children & 79 & 27.8 \\
\hline
\end{tabular}

\section{Knowledge of study participants about vasectomy}

More than half the participant $250(60.5 \%)$ reported that they had ever heard about vasectomy. Of those who had ever heard health care providers $107(43 \%)$, colleagues $89(35.6 \%)$, mass media $71(28.4 \%)$ and volunteers $34(13.6 \%)$ were the main source of information. In this study, only $147(58.8 \%)$ participants defined vasectomy correctly as "it is a men permanent contraceptive method after completing their desire number of children" and about 64 (25.6) \% defined vasectomy as 'castration'. Similarly about 39(15.6\%) described vasectomy "it is making the man impotent" (Table 3). 
Table 3

knowledge of married men about vasectomy in Debre Tabor Town, Northwest Ethiopia, December $2019(\mathrm{~N}=413)$.

\begin{tabular}{|c|c|c|}
\hline Knowledge questions & Frequency & Percent (\%) \\
\hline \multicolumn{3}{|c|}{ Vasectomy is a contraceptive method by ligating the vas deference } \\
\hline Yes & 225 & 54.5 \\
\hline No & 188 & 45.5 \\
\hline \multicolumn{3}{|c|}{ Vasectomy is permanent and irreversible? } \\
\hline Yes & 193 & 46.7 \\
\hline No & 220 & 53.3 \\
\hline \multicolumn{3}{|c|}{ Vasectomy requires minor surgical procedure? } \\
\hline Yes & 200 & 48.4 \\
\hline No & 213 & 51.6 \\
\hline \multicolumn{3}{|c|}{ Seminal fluid during ejaculation are present after vasectomy } \\
\hline Yes & 129 & 31.2 \\
\hline No & 284 & 68.4 \\
\hline \multicolumn{3}{|c|}{ Do you know how vasectomy works? } \\
\hline Yes & 109 & 26.4 \\
\hline No & 304 & 73.6 \\
\hline \multicolumn{3}{|c|}{ Vasectomy is done in Ethiopia without any charge } \\
\hline Yes & 135 & 32.7 \\
\hline No & 278 & 67.3 \\
\hline \multicolumn{3}{|c|}{ Do you know where vasectomy service is available } \\
\hline Yes & 177 & 42.9 \\
\hline No & 236 & 57.1 \\
\hline \multicolumn{3}{|c|}{ Do you know that who can use vasectomy as a family planning? } \\
\hline Yes & 203 & 49.2 \\
\hline No & 210 & 50.8 \\
\hline \multicolumn{3}{|c|}{ If yes who are they $(\mathrm{N}=203)$} \\
\hline All married men & 32 & 15.8 \\
\hline
\end{tabular}


This study identified that, only $159(38.5 \%)$ of married men with $95 \% \mathrm{Cl}$ of (33.8-43.7) had good knowledge about vasectomy (Fig. 1).

\section{Attitude of participants towards vasectomy}

Two third of the study participants $259(62.7 \%)$ had negative attitude while $154(37.3 \%)$ had positive attitude towards vasectomy (Table 4).

Table 4

Attitude of married men towards vasectomy in Debre Tabor Town, Northwest Ethiopia, December 2019(N $=413)$.

\begin{tabular}{|c|c|c|c|}
\hline Attitude questions & Agree (\%) & $\begin{array}{l}\text { Neutral } \\
(\%)\end{array}$ & $\begin{array}{l}\text { Disagree } \\
(\%)\end{array}$ \\
\hline FP is a responsibility of women & $15(3.6)$ & $2(0.5)$ & $396(95.9)$ \\
\hline $\begin{array}{l}\text { Do you believe that vasectomy negatively affects sexual } \\
\text { performance/desire }\end{array}$ & $100(24.2)$ & $232(56.2)$ & $81(19.6)$ \\
\hline Do you believe that vasectomy has series side effects & 138(33.4) & $213(51.6)$ & $62(15.0)$ \\
\hline Vasectomy is not acceptable in my religion & 294(71.2) & $52(12.6)$ & $67(16.2)$ \\
\hline Vasectomy is culturally unacceptable & $273(66.1)$ & $63(15.3)$ & $77(18.6)$ \\
\hline $\begin{array}{l}\text { I am uncertain for the future pregnancy may be happen after } \\
\text { vasectomy }\end{array}$ & $82(19.9)$ & $218(52.8)$ & $113(27.4)$ \\
\hline Vasectomy is similar with castration & $134(32.4)$ & $216(52.3)$ & $63(15.3)$ \\
\hline $\begin{array}{l}\text { Vasectomy can cause physical weakness, cannot do hard } \\
\text { work }\end{array}$ & $38(9.2)$ & $261(63.2)$ & $114(27.6)$ \\
\hline Vasectomy can ashamed the individual in the community & $84(20.3)$ & $132(32.0)$ & $197(47.7)$ \\
\hline
\end{tabular}

\section{Factors affecting level of knowledge about vasectomy among study participants}

In binary logistic regression age, educational status, wife educational status, wife occupation, number of live children and attitude of participants towards vasectomy had significant association with level of knowledge about vasectomy. In multivariable binary logistic regression analysis, after adjusting other covariables by using backward likelihood stepwise method; only educational status, number of live children and attitude remained statistically significant with participants' level of knowledge about vasectomy. 
Participants who had completed secondary education were 4.70 times more likely to have good level of knowledge about vasectomy ( $\mathrm{AOR}=4.70,95 \% \mathrm{Cl}$ : $1.26-17.55)$ as compared to those who did not attended formal education. Similarly, study participants who had attended college and above were 8.36 times higher the odds of having good knowledge about vasectomy (AOR = 8.36, 95\% Cl: 2.41-28.97) as compared to those who did not attend formal education.

Moreover participants who had 4 or more alive children were inversely correlate with level of knowledge of vasectomy ( $A O R=0.51,95 \% \mathrm{Cl}: 0.29-0.89$ ) as compared to men who had less than or equals to three alive children. Married men who had positive attitude towards vasectomy were 2.47 times more likely to had good knowledge about vasectomy $(\mathrm{AOR}=2.47,95 \% \mathrm{Cl}: 1.58-3.86)$ as compared to their counterparts(Table 5). 
Table 5

Bivariable and multivariable logistic regression on predictors of level of knowledge of married men about vasectomy in Debre Tabor Town Northwest Ethiopia, December, $2019(\mathrm{~N}=413)$.

\begin{tabular}{|c|c|c|c|c|}
\hline \multirow[t]{3}{*}{ Variables } & \multicolumn{2}{|c|}{$\begin{array}{l}\text { Knowledge of } \\
\text { vasectomy }\end{array}$} & \multirow[t]{3}{*}{ COR $(95 \% \mathrm{Cl})$} & \multirow[t]{3}{*}{ AOR (95\%Cl) } \\
\hline & Good & Poor & & \\
\hline & $N(\%)$ & $N(\%)$ & & \\
\hline \multicolumn{5}{|l|}{ Age } \\
\hline $21-30$ years & 25(32.9) & $51(67.1)$ & $\begin{array}{l}2.288(0.602- \\
8.698)\end{array}$ & $1.11(0.273-4.511)$ \\
\hline $31-40$ years & $89(45.2)$ & $108(54.8)$ & $\begin{array}{l}3.846(1.071- \\
13.81)^{\star}\end{array}$ & $2.215(0.581-8.438)$ \\
\hline $41-50$ years & $42(34.1)$ & $81(65.9)$ & $2.42(0.659-8.892)$ & $1.892(0.48-7.463)$ \\
\hline$\geq 51$ years & $3(17.6)$ & $14(82.4)$ & 1 & 1 \\
\hline \multicolumn{5}{|l|}{ Educational status } \\
\hline No formal education & $3(8.8)$ & $31(91.2)$ & 1 & 1 \\
\hline Primary & $8(21.6)$ & $29(78.4)$ & $\begin{array}{l}2.581(0.689- \\
11.79)\end{array}$ & $2.833(0.657-12.222)$ \\
\hline Secondary & $23(30.3)$ & $53(69.7)$ & $\begin{array}{l}4.484(1.244- \\
16.16)^{\star}\end{array}$ & $4.702(1.26-17.552) \star \star$ \\
\hline College and above & $125(47.0)$ & $141(53.0)$ & $\begin{array}{l}9.161(2.734- \\
30.69)^{\star}\end{array}$ & $\begin{array}{l}8.364(2.414- \\
28.979) * *\end{array}$ \\
\hline \multicolumn{5}{|l|}{ Wife education } \\
\hline No formal education & 11(19.0) & $47(81.0)$ & 1 & 1 \\
\hline Primary & 23(34.3) & $44(65.7)$ & $2.233(0.976-5.11)$ & $1.439(0.561-3.69)$ \\
\hline Secondary & $41(41.8)$ & $57(58.2)$ & $\begin{array}{l}3.073(1.424- \\
6.634)^{\star}\end{array}$ & $1.232(0.477-3.177)$ \\
\hline College and above & $84(44.2)$ & $106(55.8)$ & $\begin{array}{l}3.386(1.654- \\
6.930) *\end{array}$ & $1.052(0.384-2.885)$ \\
\hline \multicolumn{5}{|l|}{ Wife occupation } \\
\hline House wife & $50(30.5)$ & $114(69.5)$ & 1 & 1 \\
\hline Civil servant & $49(40.8)$ & $71(59.2)$ & $\begin{array}{l}1.574(0.961- \\
2.576)\end{array}$ & $0.821(0.464-1.453)$ \\
\hline
\end{tabular}

$\mathrm{AOR}=$ adjusted odd ratio; $\mathrm{Cl}$ = confidence interval; $\mathrm{COR}$ = crude odd ratio; $* *$ = statistically significant 


\begin{tabular}{|c|c|c|c|c|}
\hline \multirow[t]{3}{*}{ Variables } & \multicolumn{2}{|c|}{$\begin{array}{l}\text { Knowledge of } \\
\text { vasectomy }\end{array}$} & \multirow[t]{3}{*}{ COR $(95 \% \mathrm{Cl})$} & \multirow[t]{3}{*}{ AOR $(95 \% \mathrm{Cl})$} \\
\hline & Good & Poor & & \\
\hline & $\mathbf{N}(\%)$ & $N(\%)$ & & \\
\hline Private business & $46(48.9)$ & $48(51.1)$ & $\begin{array}{l}2.185(1.294- \\
3.688)^{\star}\end{array}$ & $1.698(0.955-3.017)$ \\
\hline $\begin{array}{l}\text { Employed at private } \\
\text { sector }\end{array}$ & $6(28.6)$ & 15(71.4) & $\begin{array}{l}0.912(0.334- \\
2.488)\end{array}$ & $0.771(0.259-2.291)$ \\
\hline Student & $8(57.1)$ & $6(42.9)$ & $\begin{array}{l}3.040(1.002- \\
9.220)^{*}\end{array}$ & $1.716(0.515-5.722)$ \\
\hline \multicolumn{5}{|l|}{ No of alive children } \\
\hline$\leq 3$ & $127(44.7)$ & $157(55.3)$ & 1 & 1 \\
\hline$\geq 4$ & $32(24.8)$ & $97(75.2)$ & $\begin{array}{l}0.408(0.257- \\
0.648)^{*}\end{array}$ & $0.517(0.298-0.898) * *$ \\
\hline \multicolumn{5}{|l|}{$\begin{array}{l}\text { Discus with partner on } \\
\text { FP }\end{array}$} \\
\hline No & $11(25.6)$ & $32(74.4)$ & 1 & 1 \\
\hline Yes & 148(40.0) & $222(60.0)$ & $\begin{array}{l}1.939(0.948- \\
3.968)\end{array}$ & $1.547(0.685-3.495)$ \\
\hline \multicolumn{5}{|l|}{ Attitude } \\
\hline Negative & $75(29.0)$ & 184(71.0) & 1 & 1 \\
\hline Positive & $84(54.5)$ & $70(45.5)$ & $\begin{array}{l}2.944(1.943- \\
4.461)^{*}\end{array}$ & $2.475(1.586-3.862)$ ** \\
\hline
\end{tabular}

\section{Discussion}

Within the sphere of family planning, vasectomy is very often ignored, despite being one of the safest, simplest, and highly effective and least expensive contraceptive methods[6].

In this study, about $60.5 \%$ of married men were ever heard about vasectomy. This is higher than study done in Turkey which is (45.1\%) participants were heard about vasectomy prior to the survey[11]. This might be due to difference in educational status of the participants since $64.4 \%$ of the respondents were Follows College and above but in the comparable studies only $21.4 \%$ were follows college and above. This finding is also higher than the 2016 EDHS report which indicated that only $23.5 \%$ married men had ever heard about vasectomy[26]. This may be due to time change since EDHS 2016 was done 5 years ago. The other reason is that our study is conducted in more urban setting while EDHS involves both rural 
and urban areas. Increased effort of governmental and non-governmental organizations to increase acceptance of long acting family planning methods may be the other reason. The data collection method and the curiosity of the data collectors in this study may be the other reason, in the EDHS, the data collectors may be non-health professionals.

Among those who had ever heard about vasectomy, only 58.8\% defined it correctly (they reported vasectomy as "a men permanent contraceptive method after completing their desire number of children"). Other responses in the survey clearly showed the presence of misconceptions about vasectomy among married men. Biases and misconceptions are the main reasons for low health service use. This is the reason why vasectomy use is low in Ethiopia. For example, about $25.6 \%$ and $15.6 \%$ of married men reported that vasectomy is similar with castration and it making the men impotent respectively.

This study showed that $38.5 \%$ of participants had good knowledge about vasectomy. This finding was in lined with the studies done in Nigeria revealed that $37.5 \%$ and $38 \%$ of the participants had good knowledge level about vasectomy $[16,21]$ respectively. In addition; our study finding was comparable with study conducted in east Wollega Zone of Oromia region, Ethiopia revealed that $35.3 \%$ of men were know about vasectomy[23].

But the finding of this study was lower than studies conducted in India showed that $70.2 \%$ and $44.6 \%$ of married men were knowledgeable about vasectomy $[29,30]$ respectively. The discrepancy may be due to difference in educational status of the participant since only $18.4 \%$ follow secondary school and $63.4 \%$ were Follows College and above but in the comparable studies $76.1 \%$ follow secondary school and $75 \%$ were Follows College and above.

According to our study knowledge about vasectomy was also lower than cross sectional study conducted in Pakistan indicate that $85.6 \%$ of the participant had adequate knowledge about vasectomy[31]. This may be socio-demographic variation between the countries like educational status of participants since $74.3 \%$ of men in Pakistan were secondary and above in their educational level.

The finding of our study was higher than study conducted in Pakistan 11\%[32]. The variation may be explained due to difference in perception towards vasectomy since $89 \%$ of married men in Pakistan perceived that vasectomy decreases male's sexual desire but in our study only $41.2 \%$ of participants had misconception about vasectomy.

This finding is also higher than study conducted in Nigeria 27.5\%[14]. The discrepancy may be explained due to difference in educational status since $64.4 \%$ of participant in this study attained college and above but in comparable study only $30.5 \%$ of participants attained above secondary school.

The result of this study revealed that as the educational status of participant increases level of knowledge acceptance concerning vasectomy also increase linearly. This finding is supported by study conducted in Gondar, northwest Ethiopia revealed that educational status (secondary and tertiary) were strongly associated with good knowledge of vasectomy[24]. This study was also consistent with a study 
done in Dangila town Northwest Ethiopia[25]. Another study in Rwanda showed as the level of attained education increased, the level of knowledge also increased in the same fashion[22]. The reason for this might be educated men are more likely to be exposed to different media. They are also more likely to comprehend the information they obtained.

According to our study finding men with 4 or more children is inversely associated with good knowledge about vasectomy. Likewise, research conducted in Gondar Northwest Ethiopia also concluded that number of children was inversely correlates with knowledge of vasectomy[24]. The possible explanation for this finding might be as the numbers of children increase the men boozer about the economic issue that cost for his family considered costly and likely it result in family quarrels and tensions. It may also have a negative impact on accessing information and continued education.

The result of this study also showed that there was a positive relationship between attitude towards vasectomy and its level of knowledge of married men. It revealed that participants who had positive attitude towards vasectomy had a good level of knowledge about it. Likewise, study conducted in Nigeria showed that there is a significant association between participants attitude towards vasectomy and their level of knowledge about it[33]. Since attitude is a key factor that influence the knowledge, men with positive attitude towards vasectomy are better able to know about it and share responsibilities in FP practice with their partner. And also, further reason may be when the individual had positive attitude; they can break myths and misconception that were negatively affecting the knowledge about vasectomy like that of vasectomy is similar with castration.

\section{Conclusion}

In conclusion, the level of knowledge of married men was low in Debre Tabor Town Northwest Ethiopia. Educational status, number of alive children and attitude towards vasectomy were significantly associated with level of knowledge about vasectomy.

\section{Recommendations}

As per finding emphasis should be given on improving the educational status of men to improve their knowledge, and positively changing the men upbringing culture right from their childhood which will also improve their attitude towards vasectomy. This in turn would motivate more men to actively participate in family planning and readily accept vasectomy as a safe and effective method of family planning. We also recommend further researcher to come up with additional and detail findings especially on qualitative aspect.

\section{Abbreviations}

AOR

Adjusted Odds Ratio 
$\mathrm{Cl}$

Confidence Interval

COR

Crude Odds Ratio

CPR

Contraceptive Prevalence Rate

EDHS

Ethiopian Demographic Health Survey

\section{Declarations}

\section{Consent for publication}

Not applicable for this publication

\section{Availability of data and materials}

The datasets used in this study are available from the corresponding author on request.

\section{Funding}

No funding sources

\section{Conflicts of Interest}

The authors declare that they have no conflict of interests regarding the publication of this paper.

\section{Ethical approval and consent for participate}

Ethical clearance was obtained from the institutional ethics committee of Debre Tabor University. A support letter request of cooperation was written to the Debre Tabor Town administration. Written consent was obtained from each study participants. Confidentiality of information and privacy was maintained.

\section{Author's Affiliations}

${ }^{1}$ Department of Midwifery, College of Health Sciences, Debre Tabor University, Debre Tabor, Ethiopia. 
${ }^{2}$ Department of Midwifery, College of Medicine and Health Sciences, Bahir Dar University, Bahir Dar, Ethiopia.

\section{Authors' Contributions}

Alemu Degu and Fentahun Yenealem, inception designed the protocol, conduct data analysis, result interpretation, manuscript drafting, wrote the paper and revised the manuscript. Bekalu Getnet and Gedefaye Nibret participate on the data collection, the editorial and data entry and analysis. All authors read and approved the final paper.

\section{Acknowledgments}

The authors would like to acknowledge Debre Tabor University for ethical clearance and technical support as well as the Debre Tabor Town administration, study participants, data collectors and supervisors.

\section{References}

1. Population RR. 2016 World Population Data Sheet. Available at http://wwwprborg/Publications/Datasheets/2016/2016-world-population-data-sheetaspxv. 2016.

2. Population Reference. Bureau. 2016 world population data sheet with a special focus on human needs and sustainable resource. 2016.

3. WHO. UNICEF, UNFPA, World Bank Group and the United Nations Population Division Trends in Maternal Mortality: 1990 to 20152015.

4. Chaudhary KB et al. Knowledge, attitude and practices regarding family planning methods among married men in urban field practice area of Ramnagar urban health center.Belagavi-A cross-sectional study. 2015;8:212-9..

5. Saifuddin A. Li L, Amy T. Maternal Deaths Averted by Contraceptive Use:Results from a Global Analysis of 172 countries. lancet.380:111 - 25.

6. United Nation Population Information Network. Report of the international conference on Population and development. Cairo. Available at .

7. Mulatu K. Mekonen W. Men's Involvement in Long Acting and Permanent Contraceptive Use in MizanAman District Southwestern Ethiopia: A Community Based Cross-Sectional Study. Health Science Journal ISSN 1791-809X. 2016;10(2:2)..

8. Butto D. Mburu S. Factors Associated with Male Involvement in Family Planning in West Pokot County, Kenya Universal. Journal of Public Health. 2015;3(4):160-8.

9. Adeyimika T. Oyedunni S., Ademola J.,et al Antecedent factors relating to the adoption of vasectomy among married men in peri-urban communities of Ibadan. Nigeria International Journal of Nursing Midwifery. 2016;8(6):47-54. 
10. Ajuwon A. Desmenuu A. Men's awareness of, Barriers to, and Intention to adopt Vasectomy among Married Men in Ibadan, Nigeria. https:/wwwresearchgatenet/peblication/313512381. 2014.

11. Kısa S. et al. Opinions and Attitudes About Vasectomy of Married Couples Living in Turkey.American Journal of Men's Health 2017, 11(3) 531 - 541..

12. Shongwe Ph et al. Assessing the Acceptability of Vasectomy as a Family Planning Option:A Qualitative Study with Men in the Kingdom of Eswatini. Int. J. Environ. Res. Public Health 2019, 16, 5158; doi:10.3390/ijerph16245158..

13. Shattuck D, et al. A Review of 10 Years of Vasectomy Programming and Research in Low Resource Settings. Global Health: Science and Practice2016;4 (4).

14. Tijani $\mathrm{K}$, Yahya $G$, et al.Attitudes and acceptance of nigerians towards vasectomy-a comparison of married men and women in lagos. East African Medical Journal. 2013;90(3)..

15. Akpamu U. Nwoke E, Osifo U, et al. Knowledge and acceptance of 'vasectomy as a method of contraception' amongst Literate Married Men in Ekpoma. Nigeria. Afr J Biomed Res. 2010;13:153-6..

16. Onasoga O. Edoni E, Ekanem J. Knowledge and attitude of men towards vasectomy as a family planning method in Edo State, Nigeria.ournal of Research in Nursing and Midwifery. 2013 Jan; 2(1):13-21.

17. Federal Ministry of Health [Ethiopia]. Health Sector Transformation Plan, 2015-2020. October 2015.

18. Marie Stopes International Ethiopia Addis Ababa. Knowledge, Attitudes and Practices (KAP) Survey, Permanent Methods of Family Planning in four regions of Ethiopia. USAID.2017.

19. Central Statistical Agency[Ethiopia]. Mini Ethiopia Demographic and Health Survey. 2019.

20. Ajeet S. Shilpa H, Jaydeep N. Denial Mode for Vasectomy among Married Men in Central India: Causes and Suggested Strategies. Psychology \& Psychotherapy. 2013;3(4)..

21. Christiana O. Sonachi C, Chinomso N. Knowledge and attitude of men about vasectomy as a method of family planning among married men working in Babcock University, Ogun state, Nigeria. International Journal of Nursing and Midwifery. 2015;7(3):30 - 5.

22. Ntakirutimana C. Umuziga P, Nikuze B, et al. Vasectomy is family planning: factors affecting uptake among men in eastern province of Rwanda. Rwanda Journal of Medicine and Health Sciences. 2019;2(2):126 - 37..

23. Awie B. Men's knowledge and attitude towards vasectomy in east Wollega zone of Oromia region, Ethiopia 2014.

24. Yenus H. Assefa G, and Atenafu A. Knowledge and Attitude of Married Men towards Vasectomy in Gondar Town. Northwest Ethiopia BAOJ Hiv. 2016;2:010.

25. Jemberie A. Abeje $G$ and Asrat A. Educational status as determinant of men's knowledge about vasectomy in Dangila town administration. Amhara regionNorthwest EthiopiaReproductive health. 2017;14(1):54.

26. Central Statistical Agency[Ethiopia]. Ethiopia Demographic and Health Survey. 2016. 
27. Town Administration of Debre Tabor [Debre Tabor]. Population size and number of household of debre tabor town. 2018.

28. Christiana Owbetu C. Chukwuma S. Nwozichi C. Knowledge and attitude of men about vasectomy as a method of family planning among married men working in Babcock University, Ogun state, Nigeria. International Journal of Nursing and Midwifery. 2015;7(3):30 - 5. .

29. Nair G. Wadke R, Relwani N, et al Knowledge and attitude of married men towards vasectomy in an urban slum of Navi Mumbai. International Journal Of Community Medicine Public Health 2017;4(12):4563-8.

30. Choudhary H. A Study to Assess the Knowledge, Attitude and Practice Regarding Vasectomy among Males, Working in Nandini Milk Dairy at Kolar. International Journal of Nursing Sciences Practice1. 2013;10:1-4.

31. Zareen H. Shahzad S, Salahhudin M. Sociodemographic and reproductive factors affecting knowledge of married men accepting vasectomy. Journal of Ayub Medical College Abbottabad 2016;28(2):323-6.

32. Naz S. Saqib M. An Assessment of the Knowledge and Attitude Towards Family Planning among Educated Married Men of Urban Islamabad, Pakistan. Pakistan Journal of Medical Research. 2017;56(3):73 - 7..

33. Christiana $\mathrm{O}$, Sonachi $\mathrm{C}$, Chinomso N. Knowledge and attitude of men about vasectomy as a method of family planning among married men working in Babcock University, Ogun state, Nigeria. International Journal of Nursing Midwifery. 2015;7(3):30-5.

\section{Figures}

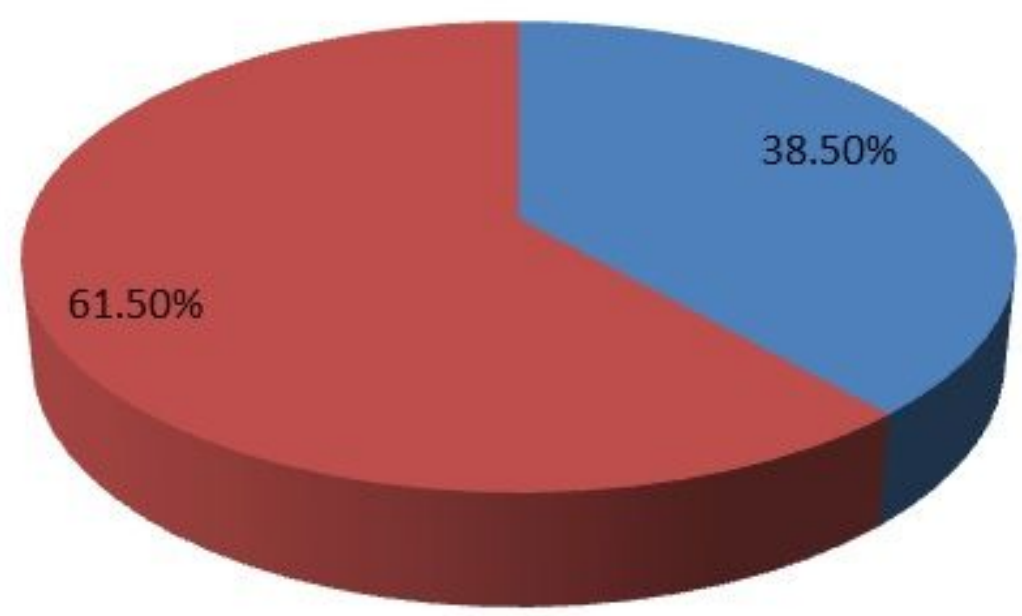

Good knowledge

a Poor knowledge 


\section{Figure 1}

Level of knowledge of married men about vasectomy in Debre Tabor Town Northwest Ethiopia, December, $2019(\mathrm{~N}=413)$. 